\title{
INTRODUCTION
}

\section{Reinventing the Invention of Culture}

Joel Robbins and David A.B. Murray

In a recent special issue of Social Analysis, Culture at the End of the Boasian Century (1997) the editors noted that the 1970s was a time of particularly intense anthropological debate about culture. They mentioned Geertz, Sahlins, Schneider and Boon as anthropologists who made some of the key theoretical contributions of that era, interrogating the meaning of the 'culture concept' and extending it in new directions. As much as those names conjure up a period of impressive accomplishment in anthropological culture theory, we feel there is an important omission from this list: Roy Wagner's The Invention of Culture, first published in 1976 (with a revised volume published in 1981). In fact, we would argue that more than twentyfive years later, this book remains highly relevant to contemporary debates on the meanings and definitions of culture in anthropological circles and, indeed, to debates on the meanings and definitions of anthropology itself.

In some ways, The Invention of Culture was very a much a book of its times in the best sense: it responded to and pushed forward debates about meaning, symbolism, structure and creativity in anthropology; it responded to a broader social scientific and humanistic hunger for work that allowed Westerners some critical purchase on their own modes of thought; and finally, although not precisely a full scale ethnography, it was the work of a master ethnographer, and was shot-through with the kind of observational confidence that was still, in that era, one of anthropology's claims on the attention of humanists and other social scientists. In other ways, however, The Invention of Culture was out of its time; a fact that perhaps allows it to be left off the kind of list that appeared in the introduction to the earlier issue of Social Analysis. In one sense, it was out of its time by seeming a bit 
old fashioned in its deployment of an argument about the radical differences between cultures, though its legacy in this area has come to look very contemporary and productive in the work, for example, of Marilyn Strathern. In another sense, it was out of its time by seeming ahead of it in its anticipation of many of themes of a post-modern anthropology that was barely on the horizon when it was published. Yet re-reading the book today, as all of our contributors do, what is perhaps most striking is how integral it is, and that integrity perhaps means that its real legacy and its challenge is timeless: one does not need to be a critical, or symbolic, or post-modern anthropologist to learn from it. One only has to encounter it on its own terms.

To mark the twenty-fifth anniversary of this publication, we invited a number of anthropologists to do just that: to encounter The Invention of Culture again and assess, interrogate and reflect upon its significance and impact in relation to contemporary theoretical debates about culture and anthropological practices. We did not want a simple festschrift. Rather, we intended to demonstrate the ongoing relevance of Wagner's theoretical engagements through critical analysis. We thus developed a couple of thematic areas that we hoped the papers would address, but as can be seen from the theoretical and ethnographic breadth and scope of the papers in this special issue, there are engagements with Wagner's work that went well beyond our initial proposals. Nevertheless, we present our two original interests as the common foundations from which these (divergent) themes have emerged.

Our first interest was to return to The Invention of Culture in order to reflect on some of its key criticisms of and propositions for the relationship between culture and anthropology. More than twenty-five years later, does anthropology continue to present culture as a kind of 'relative objectivity?' Or have we successfully 'reinvented' culture in the ways that Wagner advocates? To what extent did Wagner anticipate or predict some of the key critiques of anthropology which emerged in the 'reflexive' 1980s and the 'cultural studies' 1990s? Alternatively, in what ways may his book have been heading in different directions and hence provide us with a position from which to re-examine the new set of home truths that dominate the discipline today?

Our second interest had less to do with the book itself, and more to do with the impact it had on the subsequent practice of anthropology. How, for example, did it affect the ways in which anthropologists did fieldwork? How did it alter, challenge, clarify or obfuscate their thinking about the society in which they conducted fieldwork? What about in relation to anthropology in general? We asked the authors if they were studying or 
teaching anthropology at the time The Invention of Culture was published, and if so, how they remembered its impact on fellow students and colleagues-what kind of debates did it generate? Finally, we wanted to find out how and why they felt The Invention of Culture is still useful to think about in the new millennium.

Creativity is one of the key themes of The Invention of Culture. It is not surprising then that our contributors, who have all engaged with the book deeply, have produced a variety of original responses to the kinds of issues we, and of course Wagner's work itself, initially prompted them with. The results reflect the wide range of the book's strengths, point in a variety of new directions, and build bridges to key contemporary positions in cultural theory. We present them here not only as a tribute to the book's influence, but as a spur to others to encounter, or encounter again, one of the most original and powerful works of contemporary cultural theory. 